\title{
The Investigating Factors Affecting Breastfeeding Self-Care in Nulliparous Women Who Referred to the Health Centers in Hamadan City
}

\section{Fatemeh Shobeiri (PhD) ${ }^{1}$, Somaie Moradi Haghgoo $(\mathrm{MSc})^{2, *}$, Batool Khodakarami $(\mathrm{MSc})^{\mathbf{1}}$, Ghodratolla Roshanaie $(\mathbf{P h D})^{\mathbf{3}}$}

${ }^{I}$ Mother and Child Care Research Center, Hamadan University of Medical Sciences, Hamadan, Iran

${ }^{2}$ Department of Nursing and Midwifery, Hamadan University of Medical Sciences, Hamadan, Iran

${ }^{3}$ Department of Biostatistics, Modeling of Noncommunicable Diseases Research Center, School of Public Health, Hamadan University of Medical Sciences, Hamadan, Iran

* Corresponding Author: Somaie Moradi Haghgoo, Department of Nursing and Midwifery, Hamadan University of Medical Sciences, Hamadan, Iran. Email: s.moradihaghgoo@gmail.com

\section{Abstract}

Received: $29 / 05 / 2018$

Accepted: 14/07/2018

How to Cite this Article:

Shobeiri F, Moradi Haghgoo S, Khodakarami B, Roshanaie G.

The Investigating Factors Affecting Breastfeeding SelfCare in Nulliparous Women Who Referred to the Health Centers in Hamadan Citurses. Pajouhan Scientific Journal. 2018; 17(1): 45-50. DOI: $10.29252 /$ pj. 17.1 .45
Background and Objective: Breastfeeding is one of the main factors in the health and survival of babies and affects countless social and economic factors. The aim of this study was to determine the factors affecting breastfeeding self-care in nulliparous women who referred to the health centers in Hamadan city, Iran, 2017.

Materials and Methods: This study was performed as a descriptiveanalytic study. The study population consisted of all primiparous women who referred to health centers of Hamadan. Out of 220 nulliparous women who referred to health centers in Hamadan city due to having met the inclusion criteria were selected for the census. Data collection was done using a breastfeeding self-care questionnaire, and were analyzed using multiple linear regression using SPSS v.21 software $(\mathrm{P}<0.05)$.

Results: The findings showed that $38.6 \%$ of participants had poor self-care, $47.7 \%$ had moderate self-care and $13.6 \%$ had good self-care. The total satisfaction of the spouse, as well as the monthly income are related to the level of self-care ( $\mathrm{p}<0.001)$.

Conclusion: The full satisfaction of the spouse, as well as the monthly income, are related to the amount of breast feeding self-care. Therefore, the results of this study can be used to plan successful breastfeeding for lactating women in hospitals and comprehensive health centers.

Keywords: Breastfeeding; Nulliparous Women; Self-Care 
do: $10.29252 /$ psj.17.1.45

بررسى عوامل موثر بر خود مراقبتى در شيردهى در زنان نخستزاى مراجعه كننده به مر اكز جامع سلامت شهر هملفان

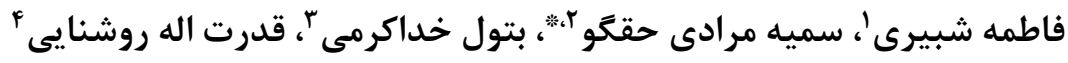 \\ ' استاد كروه مامائى، مركز تحقيقات مراقبت هاى مادر و كودى، دانشكاه علوم يزشكى همدان، همدان، ايران

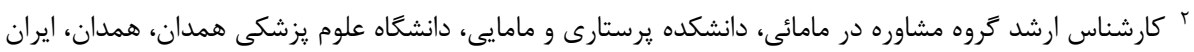

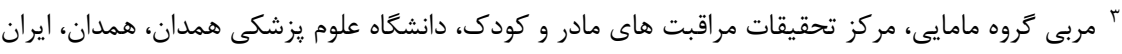

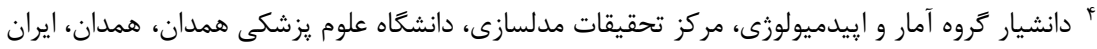 \\ * نويسنده مسئول: سميه مرادى حقكَ، دانشكده يرستارى و مامايى، دانشخاه علوم يزشكى همدان، همدان، ايران. \\ ايميل: s.moradihaghgoo@gmail.com
}

جكيله

سابقه و هدف: تغذيه با شير مادر يكى از فاكتور هاى اصلى در سلامتى و بقاء نوزادان است و از عوامل

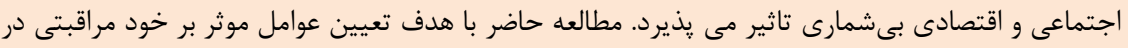

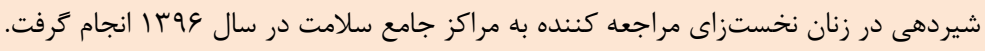

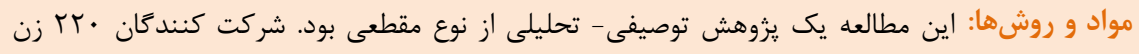

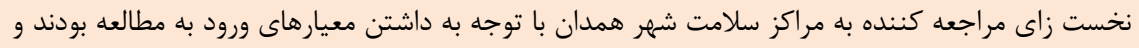

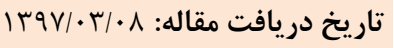

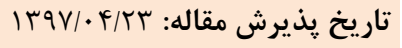
تمامى حقوق نشر براى دانشگاه علوم يزشكى همدان محفوظ است.

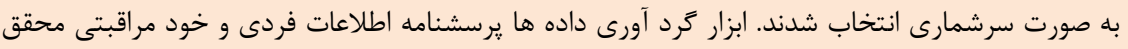

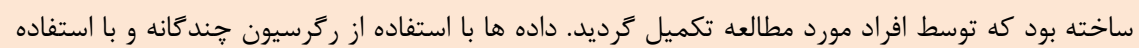

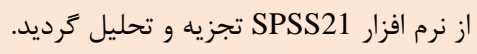

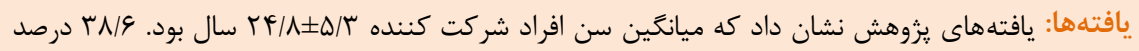

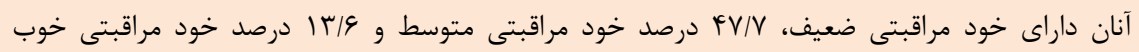

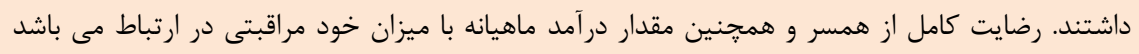
. $(\mathrm{P}<\cdot / \cdot \cdot 1)$

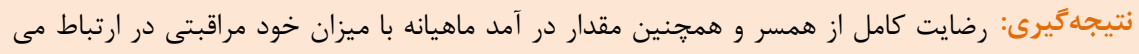

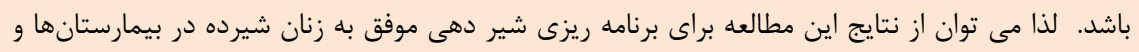

$$
\text { مراكز جامع سلامت بهره جست. }
$$

$$
\text { وازَّان كليدى: خودمراقبتى؛ زنان نخست زا؛ شيردهى }
$$

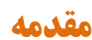

شير مادر استاندارد طلايى تغذيه شير خوار و نوزادان سالم و رسيده است و در اكثر موارد بايد تنها غذايى باشد كه تا حدود نداند

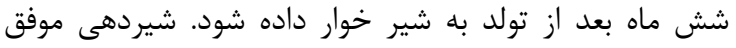

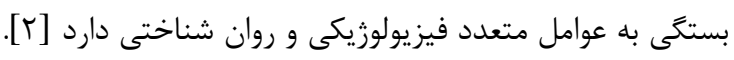
مصرف شير مادر انواع عفونت ها به ويزه عفونت هاى گوارشى و و

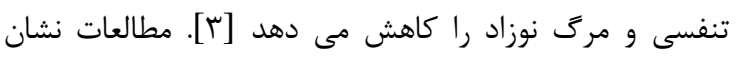

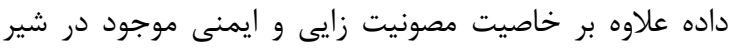

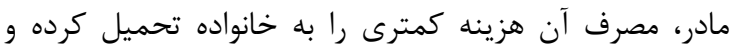

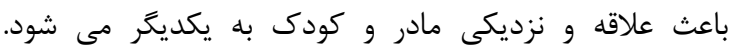

شير مادر يك استاندارد طلايى و ايدهال ماده غذايى و

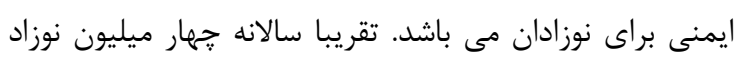

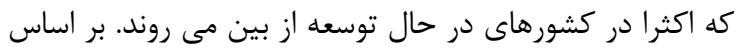

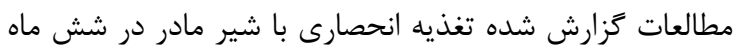

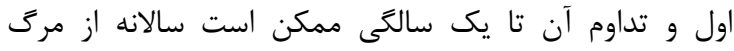

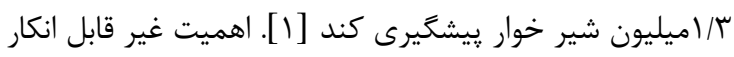

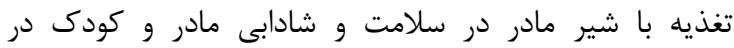

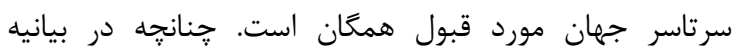

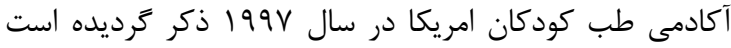


سلامت به تصادف انتخاب شدند. در مجموع ^ مراكز جامع سلامت مورد بر رسى قرار گرفت. دادههاى يزوهش از ابتداى آبان

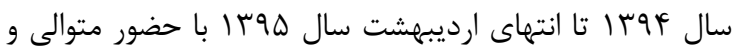
مستمر يزوهشكر در اين مراكز بهداشتى درمانى جمع آورى شد.

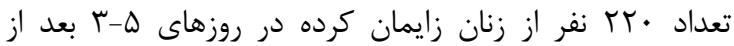

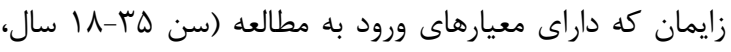

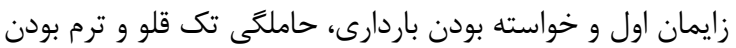

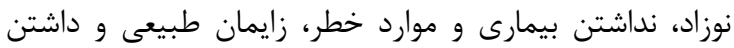

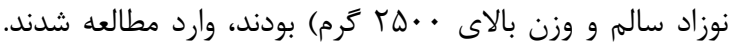
يس از معرفى يزوهشگ و توضيح در مورد هدف از از انجام مطالعه

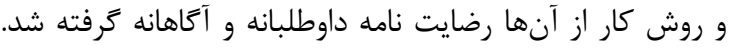

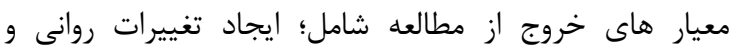

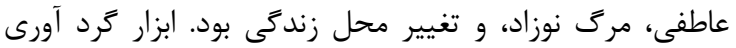

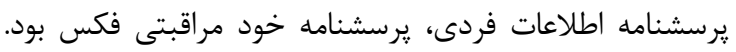
يرسشنامه خود مراقبتى شيردهى ( • اسوالى به صورت ليكرت

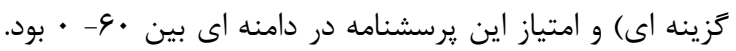

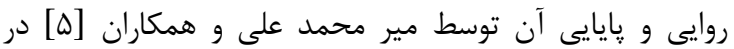
ايران سنجيده شده است. جهت تعيين روايى ابزار از روش اعتبار

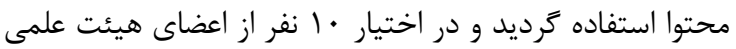

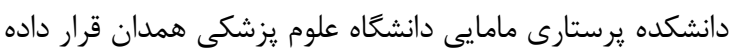

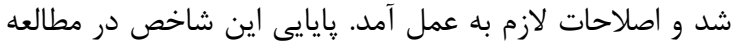

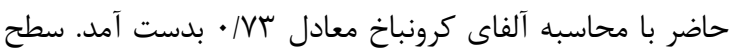
معنادارى آزمونها كمتر از له درصد در نظر گرفته شده است.

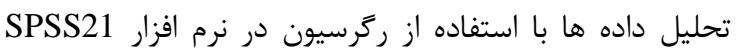

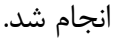

1. 1. 1. بر اساس نتايج به دست آمده در جدول ا، ميانگين و

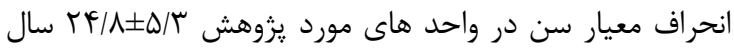

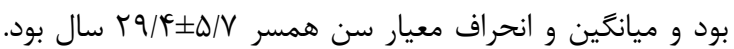

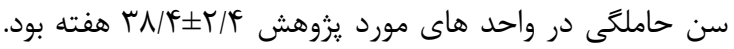
نمايه توده بدنى نيز

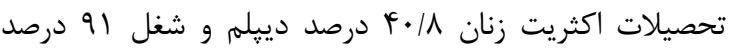

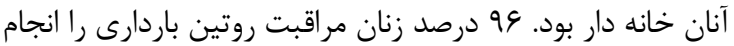

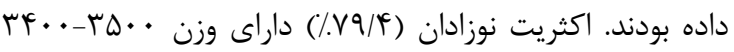

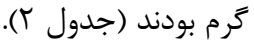

جدول (: ميانگين و انحراف معيار داده هاى كمى در واحد هاى مورد

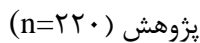

\begin{tabular}{|c|c|c|}
\hline انحراف معيار & ميانغين & متغير \\
\hline$\Delta / r$ & $T Y / \Lambda$ & سن (سال) \\
\hline$\Delta / V$ & $r q / 4$ & سن همسر (سال) \\
\hline$t / f$ & rN/F & سن حاملگى (هفته) \\
\hline$r / 9$ & $r T / q$ & (كيلو ترم/ متر مربع) BMI \\
\hline
\end{tabular}

همجنين شيردهى نه تنها سبب ارتقاء سلامت در دوره نوزادى

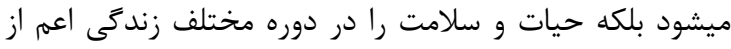

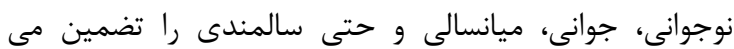

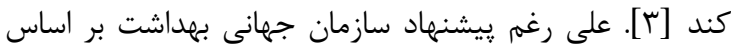

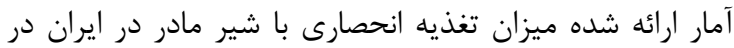

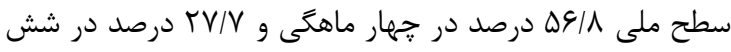

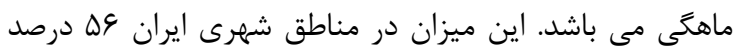

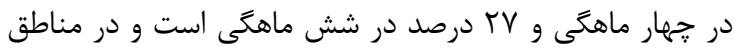

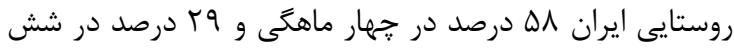

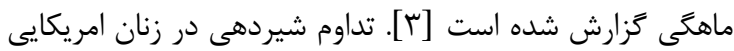

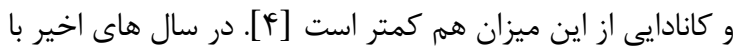

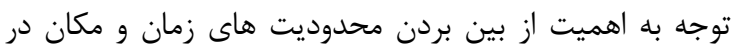

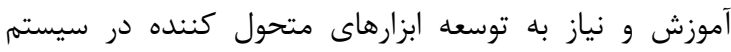

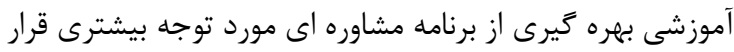

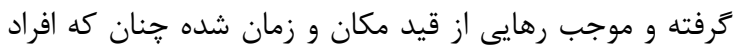

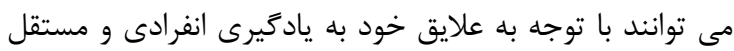

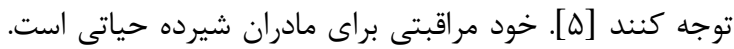

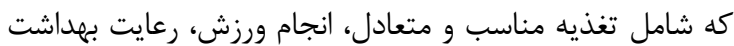

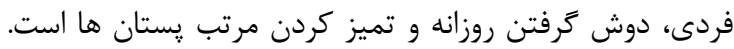

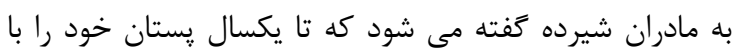

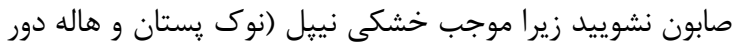

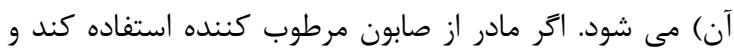

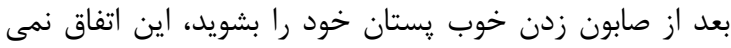

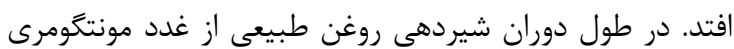
ترشح مى شود، برجستگى هاى (Montgomery Glands) كوجكى كه در روى هاله دور پِّتان بِيدا مى شود، از تكثير

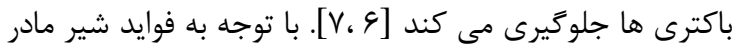

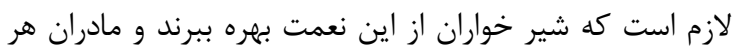

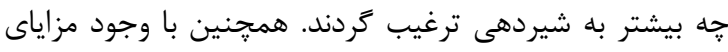

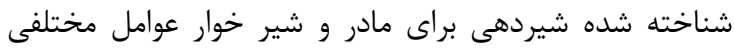

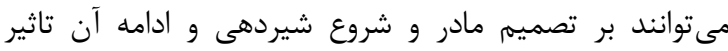

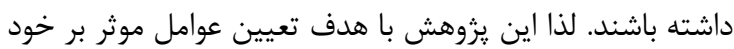

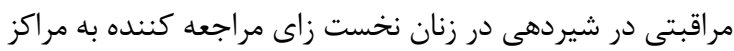
جامع سلامت همدان در سال عهب سا انجام گرديد.

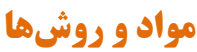

اين مطالعه يك يزوهش توصيفى- تحليلى از نوع مقطعى

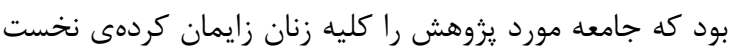
زا مراجعه كننده به مراكز سلامت شهر همدان تشكيل داد. حجم نمونه بر اساس مطالعه مير محمد على و همكاران [1]،

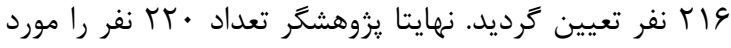

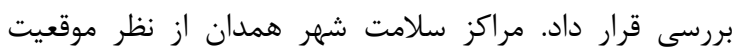

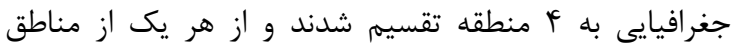

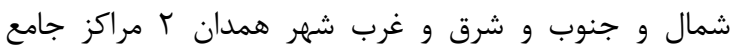


داشتن رضايت كامل از همسر، مادر خود مراقبتى بيشترى (Pارى

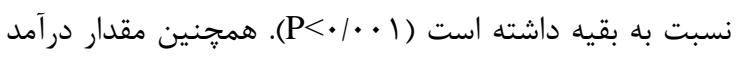
ماهيانه با ميزان خود مراقبتى در ارتباط بود به طورى كه با بالا دالا

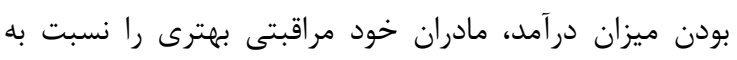

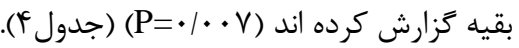

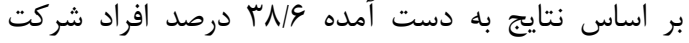

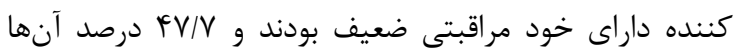

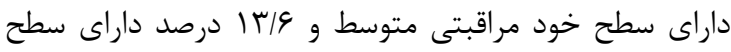

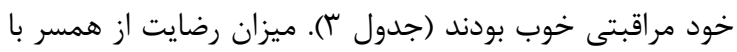

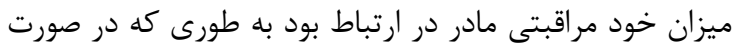

جدول r: فراوانى مطلق و نسبى برخى مشخصات دموكر افيك و مامايى در واحد هاى مورد يزوهش (•r=r.)

\begin{tabular}{|c|c|c|c|}
\hline درصد & فراوانى & سطوح متغير & متغير \\
\hline$r q / \Delta$ & $\Lambda \Lambda$ & زير دييلم & \multirow{3}{*}{ تحصيلات } \\
\hline$f \cdot / \Lambda$ & 91 & دييلم & \\
\hline $\mid N / F$ & (i) & دانشخاهى & \\
\hline$F r / 9$ & 91 & زير دييلم & \multirow{3}{*}{ تحصيلات همسر } \\
\hline$r V / r$ & ^ז & دييلم & \\
\hline$I V / V$ & rq & دانشخاهى & \\
\hline$\Lambda / 9$ & IV & شاغل & \multirow{2}{*}{ 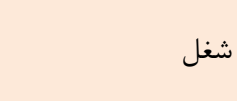 } \\
\hline $91 / \cdot$ & $r \cdot r$ & خانه دار & \\
\hline 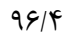 & TID & كار مند & \multirow{2}{*}{ شغل همسر } \\
\hline$r / \Delta$ & $\Delta$ & شغل آزاد & \\
\hline$V I / V$ & 109 & كمتر از ا ميليون & \multirow{3}{*}{ در آمد ماهيانه (تومان) } \\
\hline rघ/A & $\Delta 9$ & r-1 ميليون & \\
\hline$\cdot 19$ & r & بيشتر از Y ميليون & \\
\hline १६।. & rif & بله & \multirow{2}{*}{ مراقبت روتين باردارى } \\
\hline$\varphi /$ & 4 & خير & \\
\hline$f \Delta / V$ & $1 \cdot r$ & 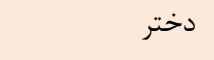 & \multirow{2}{*}{ جنسيت نوزاد } \\
\hline$\Delta F / F$ & 111 & 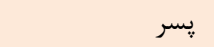 & \\
\hline$\vee q / 4$ & IVV & $r \Delta \cdots-r \Delta \cdot \cdot$ & \multirow{2}{*}{ 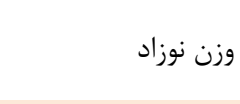 } \\
\hline$r \cdot 19$ & Fr & $>r \Delta \cdot \cdot$ & \\
\hline $1 r / 9$ & r & كاملا راضى & \multirow{4}{*}{ رضايت از همسر } \\
\hline re/A & Ar & راضى & \\
\hline$F F /$. & 90 & ناراضى & \\
\hline$\Delta / \mathcal{F}$ & it & كاملا ناراضى & \\
\hline
\end{tabular}

جدول بّ: توزيع فراوانى خود مراقبتى در واحد هاى مورد يزوهش

\begin{tabular}{|c|c|c|c|}
\hline ل درصد & فراوانى & & متغير \\
\hline rN/द & $\Lambda \Delta$ & ضعيف (نمرات S S & \multirow{3}{*}{ خود مراقبتى } \\
\hline$F V / V$ & $1 \cdot 0$ & متوسط (نمرات • • (r山-) & \\
\hline $1 \% / 9$ & $r$. & خوب (نمرات • • >) & \\
\hline
\end{tabular}

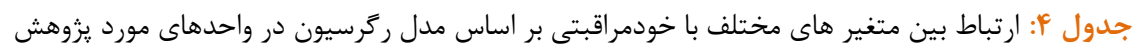

\begin{tabular}{|c|c|c|c|c|c|}
\hline \multirow{2}{*}{ P.value } & \multirow{2}{*}{$\mathbf{t}$} & \multirow{2}{*}{ ضرايب استاندارد شده } & \multicolumn{2}{|c|}{ ضرايب ركرسيونى } & \multirow{2}{*}{ متغير } \\
\hline & & & انحراف استاندارد & ضريب & \\
\hline • & $-\cdot / 9 \wedge \mu$ & $-\cdot / 1 \cdot V$ & $\cdot 1 \cdot 11$ & $-\cdot / \cdot 1 \mathrm{~V}$ & سن \\
\hline .1911 & $-.1 \cdot 10$ & $-\cdot / \cdot \cdot r$ & $.1 \cdot 10$ & שr". & سن همسر \\
\hline •/Kra & $-1 / 191$ &.$- \cdot 1 \cdot 91$ & אTMT & $-\cdot / T V G$ & شغل مادر \\
\hline$\cdot / \vee \wedge 9$ & $-\cdot / 4 \& \Lambda$ & -.1 .19 & $\cdot / \Delta V T$ & $-\cdot / 1 \Delta T$ & شغل همسر \\
\hline .1 .91 & $1 / \wedge \wedge \Delta$ & $-\cdot / I V F$ & $\cdot 11 \cdot 9$ & $\cdot / 4$ & تحصيلات مادر \\
\hline .1999 & $-\cdot / F Y \Lambda$ & $-\cdot / \cdot r \Lambda$ & $\cdot 11$ &.$- / \cdot$ \& & تحصيلات همسر \\
\hline
\end{tabular}




\begin{tabular}{|c|c|c|c|c|c|}
\hline & & & & & ادامه جدول Fi. \\
\hline و qזس/• &.$/ 909$ & $\cdot / \cdot V \Delta$ & $\cdot / \cdot 11$ & $.1 \cdot 1 \mathrm{~V}$ & نمايه توده بدنى \\
\hline $.19 Y V$ & $\cdot / 4 \wedge V$ & $\cdot / \cdot r V$ &.$/ 141$ & .1 .94 & مراقبت پِيش از باردارى \\
\hline$\cdot / \pi T \Delta$ & $1 / 195$ & $\cdot / \cdot \wedge \Lambda$ & . /ANAT & $\cdot \mid \Delta V F$ & مراقبت روتين باردارى \\
\hline$<\cdot / \cdot \cdot 1$ & - r/VTr & $-\cdot / r 9 V$ & .1 .99 & $-\cdot / r \Delta \Lambda$ & رضايت از همسر \\
\hline$\cdot / \cdot V$ & $-r / V r q$ & $-\cdot / r \cdot \Lambda$ & $1 / 19$ & $-r / T V I$ & وضعيت در آمد ماهيانه \\
\hline . MGT & $-1 / 1 T \Delta$ & $-\cdot 1 \cdot 1$ &.$/ 1 Y I$ &.$/ 1 \mathrm{rV}$ & جنسيت \\
\hline$\cdot / 419$ & - & $-\cdot / 1 \cdot 1$ & $\cdot|\cdot r|$ & $-\cdot / \cdot r \Lambda$ & سن حاملكى \\
\hline$\cdot / T V K$ & $1 / 1$ & .1 .91 & $.1 \cdot 11$ & $-\cdot / \cdot \wedge$ & وزن نوزاد \\
\hline
\end{tabular}

عامل قابل اصلاح و بالقوه اى است كه مى تواند در ارتقاى تغذيه با شير مادر نقش بسيار موثرى داشته باشد. در اين راستا لازم

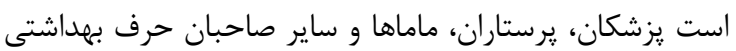

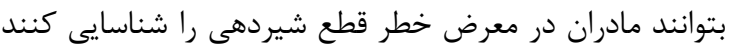
و مورد آموزش قرار دهند.

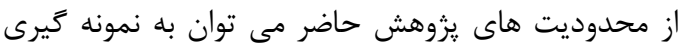

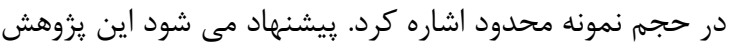
در حجم نمونه بالا بررسى شود. نقطه قوت اين طرح بررسى

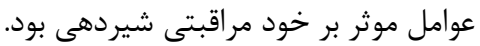

نتيجه كَيرى نتايج يزوهش حاضر نشان داد كه IN/9 درصد افراد شركت كننده داراى خود مراقبتى ضعيف، FV/V درصد آنها داراى نئن

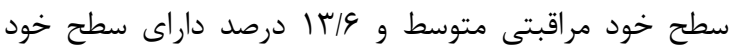
مراقبتى خوب بودند. رضايت كامل از همسر و همجنين مقدار

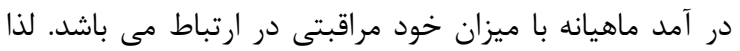

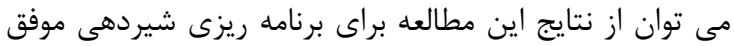

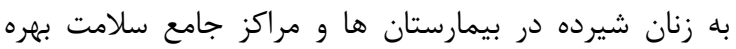

\section{تشكر و قلروراذى}

اين مقاله نتيجه پايان نامه مصوب دانشعاه علوم يزشكى

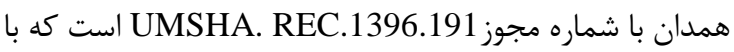
حمايت مالى معاونت محترم تحقيقات و فن آورى دانشعاه علوم يزشكى همدان انجام گرديد. بدين وسيله از معاونت محترم

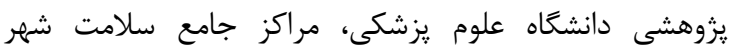

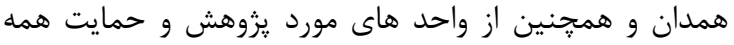

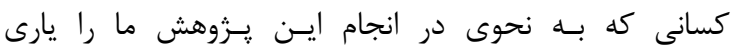
رساندند، تشكر و قدردانى مى شود.

تضاد منافع اين مطالعه براى نويسندگان هيجَّونه تضاد منافعى نداشته
يزوهش حاضر با هدف تعيين عوامل موثر بر خود مراقبتى

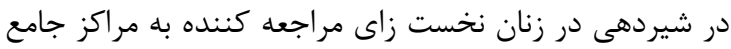

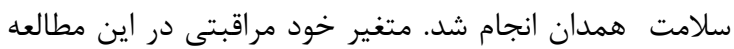

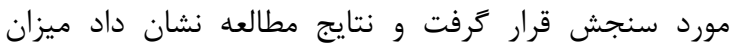

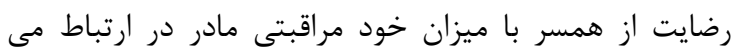

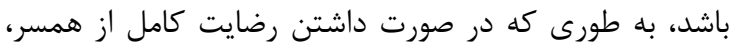

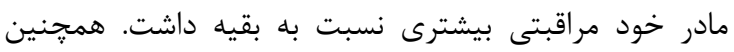

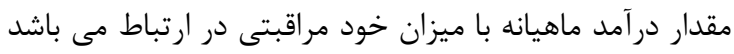

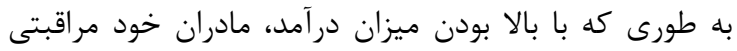

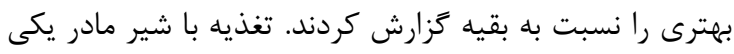

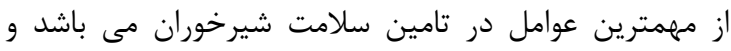

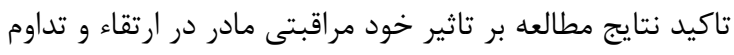

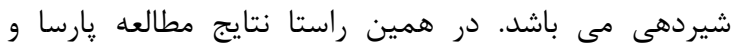

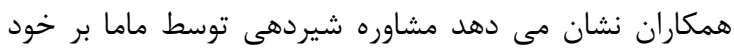

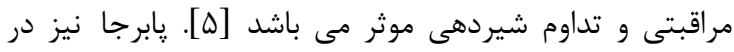

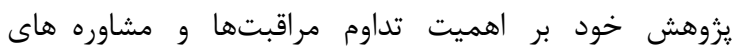

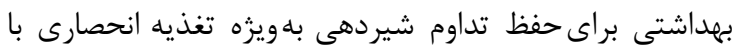

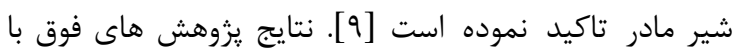

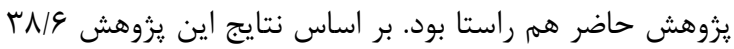

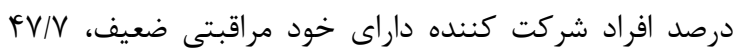

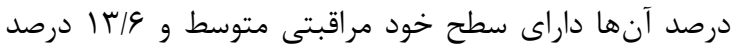

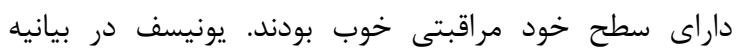
مربوط به بيمارستان هاى دوستدار كودى اعلام كرد كه مادران

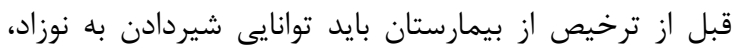

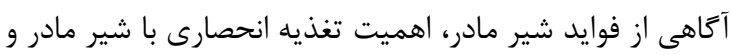

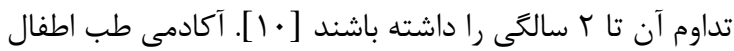

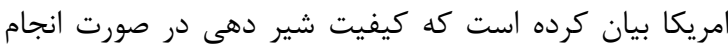

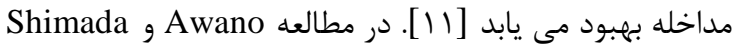

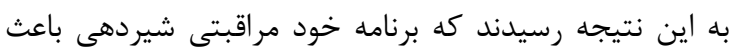

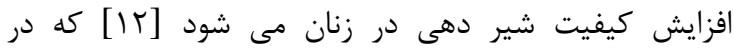
راستاى يزوهش حاضر بود.

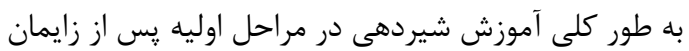

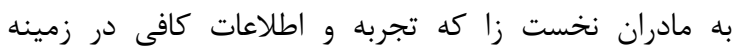
شيردهى ندارند، ضرورى به نظر مى رسد. خودمراقبتى شيردهى نهى نهري 


\section{REFERENCES}

1. Merdasi. The survey effect of message framing on breastfeeding self-efficacy and behavior among nulliparous women in Shushtar in 2015: Ahvaz Jundishapur University of Medical Sciences, Ahvaz, Iran; 2016.

2. Varaei S, Mehrdad N, Bahrani N. The relationship between self-efficacy and breastfeeding, Tehran, Iran. Journal of hayat. 2009; 15(3):31-8.

3. Hosseini SM, Masoudi R, Mamori GA. The effect of relaxation training on breastfeeding self-efficacy of mothers with preterm infants: A randomized clinical trial. Journal of Clinical Nursing and Midwifery. 2014;3(2):37-45.

4. Akbarzadeh M, Toosi M, Zare N, Sharif F. Effect of relaxation and attachment behaviors training on anxiety in first-time mothers in shiraz city, 2010: a randomized clinical trial (clinical trial article). 2013.

5. Parsa P, boojar a, Roshanai G, Bakht R. The effect breastfeeding counseling on self-efficacy and continuation breastfeeding among primiparous mothers: A randomized clinical trial. Scientific Journal of Hamadan Nursing \& Midwifery Faculty. 2016;2(24):98-104.

6. Mirmohammad A, Bahiraii A, Rahimi A. Effect of educational package on breastfeeding self-efficacy in postpartum period. Tehran University of Medical Sciences.
2014;13(2):221-8

7. Raisi Dehkordi Z, Raei M, Ghassab Shirazi M, Raisi Dehkordi SAR, Mirmohammadali M. Effect of Telephone Counseling on Continuity and Duration of Breastfeeding among Primiparus Women. Hayat. 2012;18(2):57-65.

8. Mirmohammad ali M, Bahiraii A, Rahimi A, Hashemzadeh M, Sohrabi N, Sohrabi Z. Effect of educational package on breastfeeding self-efficacy in postpartum period. 2014; 13 (4): 433-440.

9. Pabarga F, Farivar K, Kordi M, Khadivzadeh T, Mazloom S. The effect of postpartum home visit on infant's feeding pattern. Journal of Nursing and midwifery of Mashhad. 2003;5(15-16):24-31.

10. Lehane B. A Review of the Breastfeeding Support Services Provided by Public Health Nurses in Ireland. 2009.

11. Gartner LM, Morton J, Lawrence RA, Naylor AJ, O'Hare D, Schanler RJ, Eidelman AI. Breastfeeding and the use of human milk. American Academy of Pediatrics Section on Breastfeeding 2005, 115:496-506

12. Masayo A, Keiko S. Development and evaluation of a self care program on breastfeeding in Japan: a quasiexperimental study. International Breastfeeding Journal, International Breastfeeding Journal 2009; 5:9. 